\title{
LONGITUDINAL URETHRAL SLING WITH PREPUBIC AND RETROPUBIC FIXATION FOR MALE URINARY INCONTINENCE
}

\author{
CARLOS H. SCHAAL, RENATO P. COSTA, FERNANDO C. SALA, ANDRÉ P. VANNI, \\ JOSÉ P. CORTEZ
}

\author{
Section of Urology, Amaral Carvalho Hospital, Jaú, São Paulo, Brazil
}

\begin{abstract}
Objective: Description and early results of a new urethral sling technique for treatment of postprostatectomy urinary incontinence, which combines efficacy, low cost and technical simplicity.

Materials and Methods: From May 2003 to April 2004, 30 patients with moderate or total urinary incontinence, following radical prostatectomy or endoscopic resection of the prostate, underwent the new technique. The technique is based on the placement of a longitudinal-shaped sling in the bulbar urethra, measuring $4 \mathrm{~cm}$ in length by $1.8 \mathrm{~cm}$ in width, made of Dacron or polypropylene mesh, fixed by 4 sutures on each side, with 2 sutures passed with Stamey-Pereira needle by retropubic approach and 2 by prepubic approach, which are then tied over the pubis.

Pressure control was determined by interrupting the loss of infused water through a suprapubic cystostomy $60 \mathrm{~cm}$ from the pubis level.

Results: Pre-operative assessment excluded vesical instability, urethral stenosis and urinary infection. Suprapubic cystostomy was removed when the patient was able to satisfactorily void with urinary residue lower than $100 \mathrm{~mL}$, which occurred in 29 of the 30 cases. In 2 cases, there was infection of the prosthesis, requiring its removal. In 3 cases, there was the need to adjust the sling (increasing the tension), due to failure of the urinary continence. Overall, 20 of 30 (66.7\%) operated patients became totally continent, and did not require any kind of pads. Four of $30(13.3 \%)$ patients achieved partial improvement, requiring 1 to 2 pads daily and 6 of $30(20 \%)$ patients had minimal or no improvement. There was no case of urethral erosion.

Conclusion: This new sling technique has shown highly encouraging preliminary results. Its major advantage over other surgical techniques for treatment of moderate or severe stress urinary incontinence is the simplicity for its execution and low cost. A long-term assessment, addressing maintenance of continence, detrusor function and preservation of the upper urinary tract, is still needed.
\end{abstract}

Key words: urinary incontinence; men; urinary sphincter; prostheses and implants; surgical technique Int Braz J Urol. 2004; 30: 307-12

\section{INTRODUCTION}

Stress urinary incontinence (SUI) is one occasional complication following radical prostatic surgery or transurethral resection of the prostate (TURP), however, when it occurs, the consequences in terms of quality of life are dramatic to patients. Urinary incontinence following radical prostate surgery has a variable incidence, which can reach more than $30 \%$ of cases, depending on the technique employed and the criteria for its definition (1).

When the SUI is moderate or severe, surgical treatment is required. Among the techniques currently accepted and available in our setting, we have injection of periurethral bulking agents, the Silimed ${ }^{\circledR}$ 
periurethral constrictor $(4,5)$, the artificial sphincter AMS $-800^{\circledR}$ and other urethral sling techniques previously described (2). The artificial sphincter AMS$800^{\circledR}$ is considered the "gold standard" for treatment of moderate and severe SUI, however many patients continue with some degree of SUI and the need for surgical revision, after 5 years, can reach up to $50 \%$ of cases (3). Urethral bulking agents have high costs and produce quite modest results if the SUI is severe $(2,4)$. There are no published results to the moment concerning the use of the periurethral constrictor Slimed ${ }^{\circledR}$, idealized by Lima et al. $(4,5)$, for treatment of urinary incontinence following radical prostate surgery, and in the authors' experience, total continence was not achieved or the devices had to be removed due to urethral erosion.

The urethral sling surgery for treating urinary incontinence following radical prostate surgery was described by Schaeffer et al. (7), using 3 segments of vascular grafts, placed transversally to the urethra, fixed on the aponeurosis of rectus abdominis muscle, and using the leak point pressure of $150 \mathrm{~cm}$ of water as a parameter. With this technique, $56 \%$ of patients became totally continent. Several other sling techniques were proposed, using synthetic materials, cadaveric fascia or dermis, porcine skin collagen or autologous fascias. All techniques used fixation on the aponeurosis of rectus abdominis muscle or on ischiopubic rami, through bone screws (2,6-10).

The technique described here differs of the others concerning the following aspects; it uses lowcost material that is available at all hospitals, it does not require special training and is based on the principle of large extension of low-pressure urethral compression, which should improve the results and minimize the risk of urethral erosion. Additionally, it uses a bone basis for its fixation (the pubis), which reduces the risk of the sling's supporting sutures to drop over time and reduces the chance of osteitis or osteomyelitis, since no screws are introduced in the pubis.

\section{MATERIALS AND METHODS}

From May 2003 to April 2004, 30 patients with moderate or severe SUI were operated using the described technique. 27 had urinary incontinence fol- lowing radical prostate surgery and 3 had post-TURP stress urinary incontinence. Age ranged from 50 to 78 years (median 68 years) and follow-up from 2 to 12 months (median 4 months). Pre-operative assessment included urodynamic study or cystometry, cystoscopy and urine analysis in order to exclude infection. All patients had at least one year from prostate surgery and used geriatric pads or external urine collectors. Patients with urethral stenosis and patients with reduced bladder capacity or severe vesical instability were excluded.

\section{SURGICAL TECHNIQUE}

The patient is admitted on the surgery's day. A 16F Foley catheter is inserted in the urethra to fill the bladder for puncture cystostomy and for better urethral identification during dissection. An 8-cm transverse incision is performed close to the upper pubic margin and a puncture cystostomy is performed. The perineum is longitudinally incised, in an extension of approximately $5 \mathrm{~cm}$ and the bulbar urethra is dissected, preserving the bulbospongiosus muscle. The central perineal tendon is incised in order to allow better contact between the bulbar urethra and the sling and thus prevent the muscle from providing an opposing force to the sling (8).

The sling is prepared using 2 superposed segments of polypropylene or Dacron mesh, in order to assure higher steadiness, because the suture thread can easily break if it is located too close to the sling margin. The final size is $4 \mathrm{~cm}$ in length by $1.8 \mathrm{~cm}$ in width. Four nylon or 0-prolene sutures are fixed to these superposed flaps, in order to better distribute the tension (Figure-1). With a Stamey-Pereira needle, the 2 posterior sutures are passed, parallel to the urethra and next to the pubis, by posterior approach (retropubic). The other 2 anterior prepubic sutures are passed closed to the pubis as well, taking care so that the spermatic cords are not included (Figures 2 and 3 )

Retropubic sutures must be passed the closest to the pubis as possible, in order to prevent bladder perforation and to assure that soft tissues do not get interposed between the suture and the bone, which can cause pain in the postoperative period, as well as progressive loss of the sling tension due to tissue ne- 


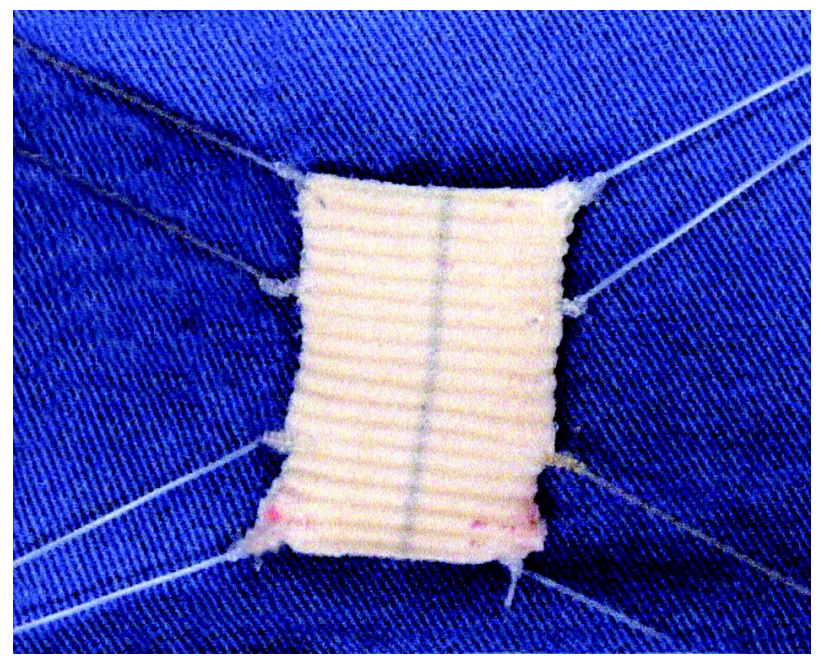

Figure 1 - Aspect of the sling ready for implantation.

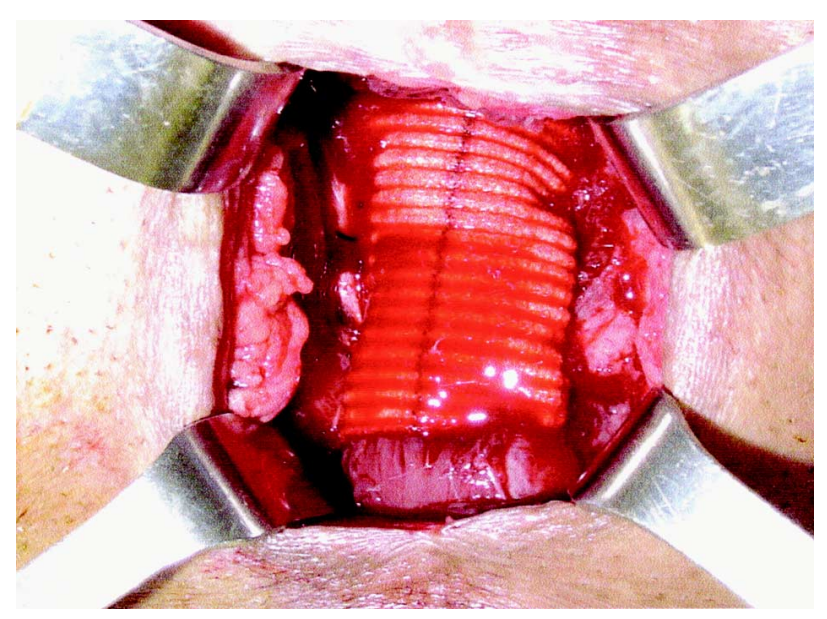

Figure 2 - Sling already fixed on the bulbar urethra.

crosis. After the suture passing, a cystoscopy is performed in order to confirm that there was no bladder perforation. First, the 4 sutures are tied over the pubis on one side, making sure that the sling is well stretched over the urethra. We remove the urethral catheter and, through the cystostomy, connect a bag containing physiological saline solution at $60 \mathrm{~cm}$ from the pubis level. We produce tension over the sling tying up the 4 sutures on the opposite side, until the moment when the leakage of saline solution through the urethra stops. The bladder is compressed to assure that the pressure was not excessive and the pa- tient can void. During the surgery, the surgical field is irrigated with a saline solution containing rifamycin and gentamicin. Perineal and abdominal incisions are closed in 2 planes. No drainage is performed. Cystostomy is kept until the patient is able to void and has residual urine lower than $100 \mathrm{~mL}$, which usually occurs within 2 to 4 days.

Patient is discharged from hospital on the day that follows surgery with the cystostomy closed. He is instructed to measure postvoiding residual urine, and the cystostomy is removed when the patient voids spontaneously, for more than 24 hours, with a residue lower than $100 \mathrm{~mL}$.

\section{RESULTS}

In 2 cases $(6.6 \%)$ there was infection in the perineal incision (both patients were diabetic) requiring the sling removal. In 1 case $(3.3 \%)$, the patient could not void after 4 weeks. We verified that the urethral leak pressure was $55 \mathrm{~cm}$ of water, and the sutures were loosened to a leak pressure of $45 \mathrm{~cm}$, but even then, the patient did not void. Bethanecol use was started with a dose of $20 \mathrm{mg} 3$ times a day,

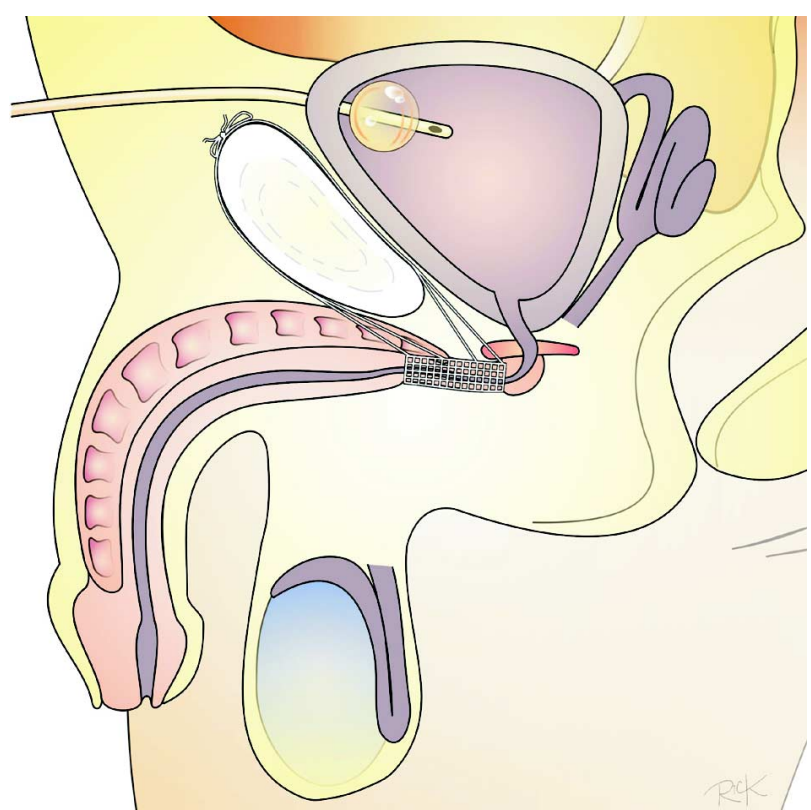

Figure 3 - Schematic drawing of a schematic sagital section showing how the sutures are passed and fixed anteriorly and posteriorly to the pubis. 
with the patient starting to void satisfactorily afterwards, with residual urine of $80 \mathrm{~mL}$, when the cystostomy was removed.

Twenty-five patients (66.6\%) are continent, with no need for pads. Four patients $(14.5 \%)$ had a significant improvement, however, with persistency of some degree of SUI, passing from use of geriatric pads to smaller absorbent pads, in the amount of 1 to 3 units daily. Six patients (20\%), including the 2 who had the slings removed, had minimal or no improvement. In 3 cases (10\%), that are currently continent, reoperation was required aiming to apply more tension to the sling after a period of 30 to 90 days, due to progressive incontinence, with all becoming continent. Four patients had previously undergone (6 months or more) placing of Marlex sling with fixation in the ischiopubic rami, unsuccessfully. The difficulty to dissect the urethra in these cases was slightly higher. Previous perineal radical prostatectomy did not impair the dissection of bulbar urethra.

\section{COMMENTS}

Male urinary incontinence, due to sphincteric insufficiency, which occurs after prostatic endoscopic resection or radical surgery, is a highly feared complication, for its consequences over the patient's quality of life. Surgical attempts to correct this picture are not recent, and in the 70's, along with the development of the artificial sphincter, Kaufman proposed several techniques, with discouraging long-term results $(13,14)$. Periurethral injections of several expansive materials showed to be effective in cases of mild or moderate SUI only (2-4). The authors' personal experience with collagen $\left(\right.$ Contigem $\left.^{\circledR}\right)$ was also disappointing. Artificial sphincters became the "gold standard" for treating moderate or severe incontinence, with optimal results in $75 \%$ to $87 \%$ of cases $(3,15)$. However, its high cost prevents its use in great part of our population. With the improvement in sling techniques, we started their use.

We ended up developing this technique because we understand that, with slings fixed on the ischiopubic rami, the required compression on the bulbar urethra often was not achieved. Cespedes \& Jacoby (8) recommend its use in cases of slight to moderate incontinence. The lack of familiarity with bone screws, as well as the fact that such material is not covered by the Brazilian Single Health System (SUS) prompted the use of fixation with sutures on the pubis.

We understand that, since the sling is an obstructive process, the detrusor muscle must be normal, and if the patient has any co-morbidity that could cause a hypocontractile bladder, a scrupulous urodynamic study must be performed pre-operatively.

Stenosis of urethra or bladder neck is a relative contra-indication, because if the patient requires internal urethrotomy, the sling would not allow the procedure to be performed, though in no case there was impossibility to catheterize the patient with a Foley catheter. Bladders with low capacity and/or low compliance are a relative contra-indication $(2,8,15)$.

Though it is not described in other techniques, in our opinion, the use of suprapubic cystostomy is quite advantageous, since it prevents the appearance of a potential ureteral lesion at the sling site due to the urethral catheter, enables the easy assessment of residual urine, and assures that the patient can empty the bladder if urinary retention occurs within the first postoperative days.

In relation to the sling material, the use of non-absorbable material is always recommended, since this surgery requires that the tension on the urethra be permanently maintained $(2,8,9)$. We believe that synthetic materials - polypropylene, Dacron, PTTE mesh, etc - are easy to handle and, since the pressure over the urethra is low and largely extended, the risk of urethral erosion is minimal. The use of aponeurosis of rectus abdominis muscle or fascia lata can be a good option as well.

In our first cases, we used polypropylene mesh and subsequently started to use segments of Dacron arterial graft, due to the higher availability of this material at our institution. The follow-up in this series is still very short, however, since results have been encouraging, in relation to other techniques previously employed by the authors (except for the artificial sphincter), we consider it a very good option for patients who have no conditions to acquire the artificial sphincter. Patients have been followed with ultrasonography of the urinary tract, urodynamic study 
and questionnaire about quality of life (16), and those will be the object of a new study when they reach a minimum of 6 months follow-up.

\section{CONCLUSION}

The technique proposed by the authors is feasible to be performed by any urologist at any hospital in any country, with low cost. The early results are similar to other techniques described. However, urethral tolerance to the sling, detrusor function and maintenance of urinary continence need still to be assessed in the medium- and long-term.

\section{REFERENCES}

1. Fowler FJ Jr, Barry MJ, Lu-Yao G, Roman A, Wasson J, Wennberg JE: Patient-reported complications and follow-up treatment after radical prostatectomy. The National Medicare experience: 1988-1990. Urology. 1993; 42: 622-9.

2. John H: Bulbourethral composite suspension: A new operative technique for post-prostatectomy incontinence. J Urol. 2004; 171: 1866-70.

3. Litwiller SE, Kim KB, Fone PD, White RW, Stone AR: Post-prostatectomy incontinence and the artificial urinary sphincter: a long-term study of patient satisfaction and criteria for success. J Urol. 1996; 156: 197580.

4. Klutke JJ, Subir C, Andriole G, Klutke GG: Long-term results after antegrade collagen injection for stress urinary incontinence following radical retropubic prostatectomy. Urology. 1999; 53: 974-7.

5. Vilar FO, Araujo LA, Lima SV: Periurethral constrictor in pediatric urology: long-term followup. J Urol. 2004; 171(6 Pt 2): 2626-8.
6. Lima SV, Araujo LA, Vilar FO: Further experience with the periurethral expander: a new type of artificial sphincter. Br J Urol. 1997; 80: 460-2.

7. Schaeffer AJ, Clemens JQ, Ferrari M, Stamey TA: The male bulbourethral sling procedure for post-radical prostatectomy incontinence. J Urol. 1998; 159: 15105.

8. Cespedes RD, Jacoby K: Male sling for postprostatectomy incontinence. Tech Urol. 2001; 7: 176-83.

9. Comiter CV: The male sling for stress urinary incontinence: a prospective study. J Urol. 2002; 167: 597601.

10. Migliari R, Pistolesi D, De Angelis M: Polypropylene sling of the bulbar urethra for post-radical prostatectomy incontinence. Eur Urol. 2003; 43: 152-7.

11. Rios LAS, Tonin RT, Panhoca R, Souza OER, Fonseca Filho LL, Mattos Jr D: Male perineal sling with autologous aponeurosis and bone fixation - description of a technical modification. Int Braz J Urol. 2003; 29: 524-7.

12. Madjar S, Jacoby K, Giberti C, Wald M, Halachmi S, Issaq $\mathrm{E}$, et al.: Bone anchored sling for the treatment of post-prostatectomy incontinence. J Urol. 2001; 165: 72-6.

13. Kaufman JJ: Surgical treatment of post prostatectomy incontinence: use of the penile crura to compress the bulbous urethra. J Urol. 1972; 107: 293-7.

14. Kaufman JJ: Treatment of post-prostatectomy urinary incontinence using a silicone gel prosthesis. Br J Urol. 1973; 45: 646-53

15. Elliott DS, Barrett DM: Mayo Clinic long-term analysis of the functional durability of the AMS800 artificial urinary sphincter: a review of 323 cases. J Urol. 1998; 159: 1206-8.

16. Herr HW: Quality of life of incontinent men after radical prostatectomy. J Urol. 1994; 151: 652-4.

Received: April 2, 2004

Accepted after revision: August 16, 2004

Correspondence address:

Dr. Carlos Hermann Schaal

Rua Luiz Paiva, 100

Jaú, SP, 17210-180, Brazil.

Fax: + 5514 3624-5155

E-mail: schaal.jau@uol.com.br 


\section{EDITORIAL COMMENT}

This work has several merits. Among them, we can include the authors' objective and concern in developing a procedure for surgical correction of postprostatectomy urinary incontinence that is feasible in our setting, according to the cost of existing alternatives, whether artificial urinary sphincter or perineal sling with bone fixation. This need becomes evident upon the performance of 30 surgeries for this purpose in a 12-month period, evidencing the repressed demand of this problem. These patients probably would not have other therapeutic alternative with the exception of this proposal.

However, before the changes described here become indiscriminately used, some data deserve to be better evaluated. There is no current agreement on the efficacy of male slings for treating postprostatectomy incontinence, basically because there is no data for interpretation (International Consultation on Incontinence, 2004). Early works did not present comparable surgical procedures, and pre-operative assessment and cure or improvement criteria were dubious. Technical modifications of procedures that are not absolutely established lack, from the beginning, a comparative term. It is evident in this se- ries of cases that improvement occurred in a significant group of patients ( 20 "continents" patients in 30 procedures). However, this improvement criterion must be seen with restrictions such as: postoperative follow-up of 2 to 12 months, with median of 4 months; the lack of reference to objective characteristics of pre-and postoperative urinary leakage; the requirement of preventive cystostomy in all cases, with an unreported number needing to maintain it for up to 14 days due to residual urine superior to $100 \mathrm{~mL}$.

Other case series of slings with bone fixation recently presented at the International Consultation on Incontinence, Paris, 2004 (Abstracts \# 445, 447 and 453), and also subjected to all interpretation restrictions mentioned above, with similar results, but with longer postoperative follow-up, even if considered insufficient, show absence of urinary obstruction and postvoiding residual urine as a common feature. If the main merit of the proposed procedure is the feasibility for its performance due to lower cost, this latter feature is, currently and beforehand, its Achilles' heel. The authors owe us results for minimal periods of 1 and 2 years, when we will be able to effectively conclude about its applicability.

Dr. Homero Bruschini Chief of Neurourology, Division of Urology Federal University of São Paulo, UNIFESP

São Paulo, SP, Brazil 